\title{
Erratum to: Attention-Deficit/Hyperactivity Disorder in Looked-After Children: a Systematic Review of the Literature
}

Renece Willis $^{1} \cdot$ Suyog Dhakras ${ }^{2} \cdot$ Samuele Cortese ${ }^{1,2,3,4}$

Published online: 11 August 2017

(C) Springer International Publishing AG 2017

Erratum to: Curr Dev Disord Rep (2017)

https://doi.org/10.1007/s40474-017-0116-z

The original version of this article unfortunately contained a mistake. The second author's name on the published version of the article was wrong; Suyog Dakhras should be changed to Suyog Dhakras. With this, the original article was corrected and the correct name is now presented above.

The online version of the original article can be found at http://dx.doi.org/ 10.1007/s40474-017-0116-z

Samuele Cortese

samuele.cortese@gmail.com

1 Academic Unit of Psychology, University of Southampton,

Southampton, UK

2 Solent NHS Trust, Southampton, UK

3 Clinical and Experimental Sciences (CNS and Psychiatry), Faculty of Medicine, University of Southampton, Southampton, UK

4 The Child Study Center, New York University Langone Medical Center, New York, NY 10016, USA 